\title{
CURRENT METHODS OF HEALTH EDUCATION BY NURSES AND ITS IMPACT ON HYPERTENSION PATIENTS; A LITERATURE REVIEW
}

\author{
Israfil Israfil 1 , Moses Glorino Rumambo Pandin 2 \\ ${ }^{1}$ Student of Doctoral Program in Nursing, Faculty of Nursing, Airlangga University \\ ${ }^{2}$ Associate Professor, Faculty of Cultural Sciences, Airlangga University \\ Email: israfil-2020@fkp.unair.ac.id
}

\begin{abstract}
Hypertension is a chronic non-communicable disease which is one of the main causes of serious cardiovascular disease death in the community. The level of treatment and health control for hypertensive patients is still not optimal due to lack of information. Aim was to identify various current methods of health education by nurses and their impact on hypertensive patients. Method Literature review research. The literature was obtained from the Scopus, Sage and PubMed databases with the keywords "Intervention" OR "Methods" AND "Nursing" AND "Hypertension". There are seven literatures that are determined to meet the requirements of the inclusion criteria. Results found three types of health education methods performed by nurses: 1) direct health education methods; nurses meet and meet face to face with patients in the form of individual teaching or training, 2) indirect health education methods; nurses are not face-toface but use telephone or mobile communication aids to convey information and send SMS about health, and use internet-based websites to convey health information, 3) combined health education methods; nurses face to face with patients and follow-up care is carried out by indirect health education methods. The impact of health education methods carried out by nurses on hypertensive patients is that the level of patient adherence increases in treatment, increased knowledge levels, better blood pressure control, healthy lifestyle practices, adherence to diet, improved quality of life, and positive nurse-patient feedback occurs. in fulfilling mutually agreed upon treatment appointments. Conclusion health education methods carried out by nurses have a very positive impact on disease management and prevention of risk factors for complications in hypertensive patients.
\end{abstract}

\section{Keywords: Health Education, Nurse, Hypertension}




\section{INTRODUCTION}

Hypertension is a chronic non-communicable disease that threatens people's health and life. Hypertension is a major risk factor for cardiovascular disease which is one of the causes of death and is considered a serious public health problem. Hypertension is a dangerous chronic cardiovascular disease which, if not handled properly, will result in complications that damage the function of other vital organs, namely the heart, brain, eyes and kidneys. The prevalence of hypertension is reported to continue to increase with the level of adherence to poor health control (Miao, J.H et al, 2020). Hypertension is the main cause of death worldwide, but the level of treatment and health control for hypertensive patients is still very low (Vedanthan, $\mathrm{R}$ et al, 2020). A factor that negatively affects treatment adherence to hypertensive patients is that patients do not read and receive information about the benefits of treatment well (Parra, D. I et al, 2019).

The World Health Organization (WHO) states that complications of hypertension have resulted in about $9.4 \%$ of deaths worldwide each year. Deaths caused by coronary heart disease and stroke are serious complications in hypertensive patients and are expected to continue to increase until they reach 23.3 million deaths in 2030. The results of basic health research (Riskesdas) of the Ministry of Health of the Republic of Indonesia in 2018 show that the prevalence of Non-Communicable Diseases includes hypertension in Indonesia has increased. Based on the results of blood pressure measurements, the incidence of hypertension has increased from $25.8 \%$ in 2013 to $34.1 \%$ in 2018.

Nurses as one of the main health workers together with medical personnel have a big role in handling hypertension in the community. A nurse is a person who has completed higher education in nursing and has the task of providing nursing care. In an effort to improve public health, nurses are tasked with providing health education and counseling to patients including hypertensive patients. Nurses as health professionals must encourage and promote health education about the importance of selfmanagement and self-actualization in hypertensive patients (Darvishpoor-, A. (2019). Hypertensive patients have a higher risk of cardiovascular disease. Intensive hypertension treatment is very important to reduce the risk. cardiovascular events and mortality in patients (Dieter, B. P et al, 2019) Health education is one of the nurses' actions to improve knowledge, attitudes, and behavior of hypertensive patients in an effort to maintain and improve their health status. Increase knowledge, attitudes and behavior of hypertensive patients will maintain the patient's health status, improve medication adherence, and prevent a high risk of hypertensive complications that can occur.

The health education methods carried out by nurses must be innovative and varied in an effort to improve the quality of nursing services, improve patient self-management, and reduce the risk of complications in hypertensive patients. The purpose of this study was to identify various current health education methods used by nurses and their impact on hypertensive patients.

\section{METHOD}

The design of this research is a literature review. The literature used is a research article on the latest health education methods by nurses in hypertensive patients that has been published in international journals. Literature searches were performed on the Scopus, Sage and PubMed databases with the keywords "Intervention" OR "Methods" AND "Nursing" AND "Hypertension". The literature used is those 
that meet the inclusion criteria, namely Population is hypertensive patients, Intervention: health education methods by nurses, Outcome: problems in hypertensive patients are resolved, Time: 2019-2021.

\section{RESULTS}

Table 1. Distribution of current health education methods by nurses and their impact on hypertensive patients

\begin{tabular}{|c|c|c|}
\hline Researcher, Year & Health Education Methods & Impact on Hypertensive Patients \\
\hline $\begin{array}{l}\text { Mattei da Silva et al, } \\
2020\end{array}$ & $\begin{array}{l}\text { Case management : nurse } \\
\text { consultation, telephone } \\
\text { contact, home visits, and } \\
\text { referral as appropriate }\end{array}$ & $\begin{array}{l}\text { Such case management improves patient } \\
\text { adherence to hypertension treatment }\end{array}$ \\
\hline Pour, E. R et al, 2020 & $\begin{array}{l}\text { SMS-based } \\
\text { education }\end{array}$ & $\begin{array}{l}\text { SMS-based education is effective in significantly } \\
\text { promoting medication adherence in hypertensive } \\
\text { patients }\end{array}$ \\
\hline Oyewole et al, 2020 & $\begin{array}{l}\text { Training on knowledge and } \\
\text { lifestyle modification }\end{array}$ & $\begin{array}{l}\text { The training program increases the knowledge of } \\
\text { hypertensive patients and improves the ability to } \\
\text { practice a healthy lifestyle for hypertensive } \\
\text { patients }\end{array}$ \\
\hline $\begin{array}{l}\text { Abu-El-Noor et al, } \\
2020\end{array}$ & $\begin{array}{l}\text { Health education using by } \\
\text { phones / telephones }\end{array}$ & $\begin{array}{l}\text { Health education using by phones resulted in } \\
\text { increased adherence to hypertension treatment; } \\
\text { medication adherence, diet, and keeping promises }\end{array}$ \\
\hline $\begin{array}{l}\text { Romero Guevara et al, } \\
2019\end{array}$ & Individual Teaching & $\begin{array}{l}\text { Individual teaching can improve adherence to the } \\
\text { therapeutic regimen of patients with hypertension } \\
\text { and / or type- } 2 \text { diabetes. }\end{array}$ \\
\hline Stephen et al, 2019 & $\begin{array}{l}\text { Case management; face to } \\
\text { face consultation and } \\
\text { telephone consultation }\end{array}$ & $\begin{array}{l}\text { Such case management results in better blood } \\
\text { pressure control in hypertensive patients. }\end{array}$ \\
\hline Kao, C. W et al, 2019 & $\begin{array}{l}\text { Website-based independent } \\
\text { titration program }\end{array}$ & $\begin{array}{l}\text { A web-based titration program can provide } \\
\text { immediate feedback to patients on how to control } \\
\text { blood pressure and manage disease at home. This } \\
\text { program not only lowers the average blood } \\
\text { pressure but also improves the quality of life for } \\
\text { hypertensive patients }\end{array}$ \\
\hline
\end{tabular}

\section{DISCUSSION}

Health education is one of the nurses' actions in increasing patient and community knowledge to prevent and treat a disease. Health education on certain topics is very effective in increasing a person's knowledge and behavior to suit health behavior. Good knowledge about non-communicable chronic diseases including hypertension will increase a person's ability to manage and prevent complications of these diseases. The research results of Almomani et al (2021) suggest the importance of including health promotion education related to chronic non-communicable diseases using a variety of innovative approaches to increase knowledge and behavior of healthy individuals. 
Based on the research results in Table 1, it is known that there are several current methods of health education carried out by nurses in an effort to manage cases of hypertensive patients. The results of these various studies can be grouped into three current health education methods carried out by nurses, namely direct health education methods, indirect health education methods, and combination health education methods.

The direct health education method is a conventional health education method where nurses and patients meet face to face and discuss with each other to find solutions to health problems experienced by patients. Based on the research results found in table 1, direct health education methods can be carried out in the form of individual teaching (Romero Guevara et al, 2019) and training (Pour, E.R et al, 2020). Direct education methods are generally carried out in health care facilities when patients undergo examination and treatment or in special service areas where nurses are present with patients to provide health education and discuss both individually and in groups.

Direct health education methods have been recognized as having benefits for patients. In an effort to manage cases of hypertension, health education methods directly have a significant effect on changes in knowledge, attitudes, and behavior of hypertensive patients. The results of the research by Romero Guevara et al (2019) prove that direct health education methods with individual teaching can improve hypertension patient compliance in following the prescribed therapeutic regimen. Direct education methods with knowledge training programs and lifestyle modifications have been shown to increase knowledge of hypertensive patients and increase their ability to adopt healthy lifestyle practices as recommended (Oyewole et al, 2020). The results of the training action show a significant increase in knowledge and skills in hypertensive patients (Baumann, A. A et al, 2019). Nurses realize that the success of health education in hypertensive patients is not only determined by patient behavior, but also on the health education methods provided in the health care system and hypertension patient care (Gorina, M et al, 2019). The availability of supporting care facilities is important even though the patient's knowledge of prevention is generally good. Practices such as motivational counseling and better educational tools are needed to promote health in hypertensive patients (Fitzsimons, D et al, 2020). The experience of hypertensive patients in their own care is also influenced by the knowledge, beliefs, presence of nurses, actions, and opportunities for patients to take action according to their beliefs, customs, and cultural practices against hypertension (Najar, J. P. Á et al, 2020 ).

The indirect health education method is a health education method in which the nurse does not meet and does not meet face to face with the patient to provide health information. The indirect health education method uses tools as an intermediary medium to convey health information to patients. Based on the results of research in table 1.shows that there are several indirect health education methods that nurses can do in handling hypertensive patients, namely the website-based independent titration program (Kao, C.W et al, 2019), health education using cellphones / telephones (Abu -El-Noor et al, 2020), and SMSbased health education (Pour, E. R et al, 2020).

Health education methods do not directly provide good benefits for hypertensive patients. The results of the study by Kao, C. W et al, 2019 found that indirect health education methods in the form of a web-based independent titration program can provide direct feedback to patients on how to control blood pressure and manage disease at home. This program not only lowers the average blood pressure but also improves the quality of life for hypertensive patients. Research by Abu-El-Noor et al., 2020 found that 
health education using cell phones resulted in increased compliance of hypertensive patients with hypertension treatment; adherence to medication, diet, and accuracy of patient appointments to meet nurses in obtaining health services. The results of the study by Pour, E.R et al, 2020 found that SMS-based indirect health education was effective in promoting treatment adherence in hypertensive patients. The use of technology media in health education methods can have a positive impact to support self-management of hypertension, especially in medication adherence (Still, C. H et al, 2020. Health education management on self-medication for hypertensive patients with the support of culturally adapted smartphones is a solution effective to produce a significant reduction in systolic blood pressure in uncontrolled hypertensive patients (Chandler, J et al, 2019). Hypertensive patients from low socioeconomic groups are considered to receive health education with this method. become an important target group for direct health education method interventions in the prevention of cardiovascular disease risk (Lee, L \& Young C, 2020). Low levels of knowledge about cardiovascular disease are found in patients with low income and low education levels. $h$. This condition is an independent factor in the high level of cardiovascular risk that nurses must pay attention to in providing health education with appropriate methods (Liu, Q et al, 2020).

The combination health education method is a method of health education that is carried out jointly, either directly or indirectly, using intermediary media in conveying health information to patients. Based on the research results in Table 1, it shows that there are several combination health education methods that nurses can do in case management of hypertensive patients. Combined health education methods that can be done are face-to-face consultation and telephone consultation (Stephen et al, 2019), and nurse consultation, telephone contact, home visits, and making referrals (Mattei da Silva et al, 2020).

Combined health education methods have benefits in case management of hypertension. The results of the study by Mattei da Silva et al (2020) found that the act of consulting nurses, telephone contacts, home visits, and appropriate referrals had a significant effect on increasing patient compliance in carrying out hypertension treatment. Research by Stephen et al (2019) found that face-to-face consultation and telephone consultation can result in better blood pressure control in hypertensive patients. Stephen, $\mathrm{C}$ et al, 2019 conducted a study to test the effectiveness of nurse-led interventions to reduce blood pressure in adults with hypertension and high cardiovascular risk. These interventions involve health education methods, namely face-to-face and telephone consultations with nurses to assess lifestyle risks and develop an action plan for hypertensive patients. The results showed that there were better changes in blood pressure and lifestyle of hypertensive patients and increased adherence to treatment. Lifestyle changes and good physical activity can have an impact on changing blood pressure to normal in hypertensive patients (Chen, M. L et al, 2020). "Worth the Walk" is a physical activity for walking according to culture that can be done to prepare hypertension patients in preventing stroke complications (Menkin, J. A., 2019). The results of research by Moradi, M. et al (2019) found that the combination health education method using self-management programs based on the $5 \mathrm{~A}$ model has better effectiveness in increasing self-efficacy in hypertensive patients. The combination health education method with self-management programs based on the 5 A model according to Moradi, M. et al (2019) is 1) Assessing or assessing the knowledge, beliefs and behavior of patients about hypertension, 2) providing advice and informing patients about the dangers of associated risks. hypertension disease that they experience, 3) make an agreement with the patient about the treatment action to be carried out, 4) provide health education assistance to patients and their families, both individually in health service facilities and in groups. Health education is given in the form of 
lectures and question and answer methods related to measuring blood pressure, normal range of blood pressure, physical activity, healthy diet and others, 5) managing patient performance and assessing using phone calls to evaluate the progress of self-management of hypertensive patients at home.

Handling hypertension cases with various health education methods performed by nurses is an important action for the health and safety of hypertensive patients. Research has shown that nurse-led hypertension case management is very effective in treating patients with uncontrolled blood pressure in the community. The results of research by Miao, J.H et al., 2020 prove that nurse-led hypertension management is effective in improving hypertension patient self-care behavior and increasing patient satisfaction with health services. Research by Konlan, K. D et al (2020) shows that hypertensive patients perceive nurses as a key player in the management of hypertensive patients. The hypertensive patient as a prescription said the nurse was present and responsive to the patient's needs, had a high degree of confidentiality about the patient's health condition, provided efficient health education, chose a therapeutic work environment, and ensured effective communication and provided ethical professional practice. The distribution of nursing staff across shifts should be of concern in the care of hypertensive patients in particular and the care of the patient as a whole. Another study also evaluated the effects of a nurse-based hypertension management program. Nurse-led hypertension case management is proven to support costeffectiveness, support policies, and have sustainable health care practices (Spies, L. A et al, 2019). Research by Vedanthan, $\mathrm{R}$ et al, 2020 found that nurse-managed hypertension treatments can control a significant decrease in blood pressure in hypertensive patients. Retention in care remains a challenge for nurses who provide health services. If the results of this study are reproduced in a prospective trial setting with increased retention in care, then this condition could be an effective strategy for improving the care of hypertensive patients worldwide (Vedanthan, R et al, 2020).

\section{CONCLUSION}

There are three current health education methods performed by nurses in the management of hypertensive patients, namely; direct health education methods, indirect health education methods, and combined health education methods. Direct health education methods are carried out by way of nurses meeting and meeting face to face with patients in the form of individual teaching or training. Health education methods are not directly carried out without face to face but using electronic communication media aids by telephone or cellphone to deliver information, or using internet-based websites to convey health information. The combination health education method is carried out by means of nurses meeting face to face with patients and carrying out follow-up care with indirect health education methods using communication media aids. The impact of health education methods carried out by nurses on hypertensive patients is that patients have a good level of adherence to treatment, have increased knowledge, better blood pressure control, healthy lifestyle practices, adherence to diet, improved quality of life for hypertensive patients and patients have good feedback and keep every nursing appointment agreed upon with the nurse. 


\section{REFERENCES}

Abu-El-Noor, N. I., Aljeesh, Y. I., Bottcher, B., \& Abu-El-Noor, M. K. (2020). Impact of a mobile phone app on adherence to treatment regimens among hypertensive patients: A randomised clinical trial study. European Journal of Cardiovascular Nursing. https://doi.org/10.1177/1474515120938235

Almomani, M. H., Rababa, M., Alzoubi, F., Alnuaimi, K., Alnatour, A., \& Ali, R. A. (2021). Effects of a health education intervention on knowledge and attitudes towards chronic non-communicable diseases among undergraduate students in Jordan. Nursing Open, 8(1), 333-342. https://doi.org/10.1002/nop2.634

Baumann, A. A., Mutabazi, V., Brown, A. L., Hooley, C., Reeds, D., Ingabire, C., Ndahindwa, V., Nishimwe, A., Cade, W. T., de las Fuentes, L., Proctor, E. K., Karengera, S., Schecthman, K. B., Goss, C. W., Yarasheski, K., Newsome, B., Mutimura, E., \& Davila-Roman, V. G. (2019). Dissemination and Implementation Program in Hypertension in Rwanda: Report on Initial Training and Evaluation. Global Heart, 14(2), 135-141. https://doi.org/10.1016/j.gheart.2019.06.001

Chandler, J., Sox, L., Kellam, K., Feder, L., Nemeth, L., \& Treiber, F. (2019). Impact of a culturally tailored mhealth medication regimen self-management program upon blood pressure among hypertensive hispanic adults. International Journal of Environmental Research and Public Health, 16(7), 1-13. https://doi.org/10.3390/ijerph16071226

Chen, M. L., Hu, J., McCoy, T. P., Letvak, S., \& Ivanov, L. (2020). Associations of lifestyle intervention effect with blood pressure and physical activity among community-dwelling older Americans with hypertension in Southern California. International Journal of Environmental Research and Public Health, 17(16), 1-9. https://doi.org/10.3390/ijerph17165673

Darvishpoor-, A. (2019). Self - Actualization: Self - Care Outcomes among Elderly Patients with Hypertension. https://doi.org/10.4103/ijnmr.IJNMR

Dieter, B. P., Daratha, K. B., McPherson, S. M., Short, R., Alicic, R. Z., \& Tuttle, K. R. (2019). Association of acute kidney injury with cardiovascular events and death in systolic blood pressure intervention trial. American Journal of Nephrology, 49(5), 359-367. https://doi.org/10.1159/000499574

Fitzsimons, D., Stępińska, J., Kerins, M., F Piepoli, M., Hill, L., Carson, M. A., \& Prescott, E. (2020). Secondary prevention and cardiovascular care across Europe: A survey of European Society of Cardiology members' views. European Journal of Cardiovascular Nursing, 19(3), 201-211. https://doi.org/10.1177/1474515119877999

Gorina, M., Limonero, J. T., \& Álvarez, M. (2019). Educational diagnosis of self-management behaviours in patients with diabetes mellitus, hypertension and hypercholesterolaemia based on the PRECEDE model: Qualitative study. Journal of Clinical Nursing, 28(9-10), 1745-1759. https://doi.org/10.1111/jocn.14794

Kao, C. W., Chen, T. Y., Cheng, S. M., Lin, W. S., \& Chang, Y. C. (2019). A web-based self-titration program to control blood pressure in patients with primary hypertension: Randomized controlled trial. Journal of Medical Internet Research, 21(12), 1-13. https://doi.org/10.2196/15836

Konlan, K. D., Armah-Mensah, M., Aryee, R., \& Appiah, T. A. (2020). Expectation and Satisfaction with Nursing Care among Hypertensives Receiving Care at a Resource-Constrained Hospital in Ghana. Nursing Research and Practice, 2020. https://doi.org/10.1155/2020/6094712 
Lee, L., \& Young, C. (2020). A Two-step Clustering Approach for Measuring Socioeconomic Factors Associated with Cardiovascular Health among Older Adults in South Korea. Korean Journal of Adult Nursing, 32(6), 551-559. https://doi.org/10.7475/KJAN.2020.32.6.551

Liu, Q., Huang, Y. J., Zhao, L., Wang, W., Liu, S., He, G. P., Liao, L., \& Zeng, Y. (2020). Association between knowledge and risk for cardiovascular disease among older adults: A cross-sectional study in China. International Journal of Nursing Sciences, 7(2), 184-190.

https://doi.org/10.1016/j.jinss.2020.03.008

Mattei da Silva, Â. T., de Fátima Mantovani, M., Castanho Moreira, R., Perez Arthur, J., \& Molina de Souza, R. (2020). Nursing case management for people with hypertension in primary health care: A randomized controlled trial. Research in Nursing and Health, 43(1), 68-78. https://doi.org/10.1002/nur.21994

Menkin, J. A., McCreath, H. E., Song, S. Y., Carrillo, C. A., Reyes, C. E., Trejo, L., Choi, S. E., Willis, P., Jimenez, E., Ma, S., Chang, E., Liu, H., Kwon, I., Kotick, J., \& Sarkisian, C. A. (2019). "Worth the Walk": Culturally Tailored Stroke Risk Factor Reduction Intervention in Community Senior Centers. Journal of the American Heart Association, 8(6). https://doi.org/10.1161/JAHA.118.011088

Miao, J. H., Wang, H. S., \& Liu, N. (2020). The evaluation of a nurse-led hypertension management model in an urban community healthcare: A randomized controlled trial. Medicine, 99(27), e20967. https://doi.org/10.1097/MD.0000000000020967

Moradi, M., Nasiri, M., Jahanshahi, M., \& Hajiahmadi, M. (2019). The effects of a self-management program based on the $5 \mathrm{~A}$ 's model on self-efficacy among older men with hypertension. Nursing and Midwifery Studies, 8(1), 21-27. https://doi.org/10.4103/nms.nms_97_17

Najar, J. P. Á., Sanabria, M. L. V., \& Pita, A. P. P. (2020). Report of the experience of living with high blood pressure in light of the theory of caring. Investigacion y Educacion En Enfermeria, 38(2). https://doi.org/10.17533/UDEA.IEE.V38N2E10

Oyewole, O., Olorunfemi, O., Ojewole, F., \& Olawale, M. (2020). Effect of a training programme on knowledge and practice of lifestyle modification among hypertensive patients attending out-patient clinics in lagos. Iranian Journal of Nursing and Midwifery Research, 25(1), 58-64. https://doi.org/10.4103/ijnmr.IJNMR_201_18

Parra, D. I., Romero Guevara, S. L., \& Rojas, L. Z. (2019). Influential factors in adherence to the therapeutic regime in hypertension and diabetes. Investigacion y Educacion En Enfermeria, 37(3). https://doi.org/10.17533/UDEA.IEE.V37N3E02

Pour, E. R., Aliyari, S., Farsi, Z., \& Ghelich, Y. (2020). Comparing the effects of interactive and noninteractive education using short message service on treatment adherence and blood pressure among patients with hypertension. Nursing and Midwifery Studies, 9(2), 68-76. https://doi.org/10.4103/nms.nms_82_19

Romero Guevara, S. L., Parra, D. I., \& Rojas, L. Z. (2019). »teaching: Individual» to increase adherence to therapeutic regimen in people with hypertension and type-2 diabetes: Protocol of the controlled clinical trial ENURSIN. BMC Nursing, 18(1), 1-9. https://doi.org/10.1186/s12912-019-0344-0

Spies, L. A., Nanyonga, R. C., \& Nakaggwa, F. (2019). Nurse-led interventions in the interim: waiting on universal health coverage. International Nursing Review, 66(4), 549-552.

https://doi.org/10.1111/inr.12558 
Stephen, C., Halcomb, E., Mclnnes, S., Batterham, M., \& Zwar, N. (2019). Improving blood pressure control in primary care: The ImPress study. International Journal of Nursing Studies, 95, 28-33. https://doi.org/10.1016/.ijnurstu.2019.03.019

Still, C. H., Margevicius, S., Harwell, C., Huang, M. C., Martin, L., Dang, P. B., \& Wright, J. T. (2020). A community and technology-based approach for hypertension self-management (Coachman) to improve blood pressure control in african americans: Results from a pilot study. Patient Preference and Adherence, 14, 2301-2313. https://doi.org/10.2147/PPA.S283086

Vedanthan, R., Kumar, A., Kamano, J. H., Chang, H., Raymond, S., Too, K., Tulienge, D., Wambui, C., Bagiella, E., Fuster, V., \& Kimaiyo, S. (2020). Effect of nurse-based management of hypertension in Rural Western Kenya. Global Heart, 15(1), 1-11. https://doi.org/10.5334/GH.856 